\title{
miR-340 Promotes Retinoblastoma Cell Proliferation, Migration and Invasion Through Targeting WIFI
}

\section{Kun Li \\ Fengmei Han \\ Yanping Wu \\ Xue Wang}

Department of Pediatric Ophthalmology, Cangzhou Central Hospital, Cangzhou, 06I00I, People's Republic of China
Correspondence: Kun Li

Department of Pediatric Ophthalmology, Cangzhou Central Hospital, \#16 Xinhua

West Road, Cangzhou, 06I00I, People's

Republic of China

Email likun6686@I63.com
Background: MicroRNAs (miRNAs) function as important regulators of gene expression involved in tumor pathogenesis, including retinoblastoma. However, the expression profiles and potential roles in retinoblastoma are still largely unclear.

Material and Methods: Differentially expressed miRNAs (DEmiRs) and genes (DEGs) in retinoblastoma were extracted from Gene Expression Omnibus (GEO) repository. Expression levels of miR-340 and WIF1 were detected in retinoblastoma tissues and cell lines by qRTPCR. Both gain-of-function and loss-of-function experiments were performed to explore the effects of miR-340 on cell proliferation, migration and invasion. Bioinformatics analysis and luciferase reporter assay were used to explore the interaction between miR-340 and WIF1. Results: A total of 11 DEmiRs were identified in retinoblastoma tissue and blood samples. Among them, we validated that miR-340 was the most highly expressed miRNA and correlated with tumor size, ICRB stage and optic nerve invasion. miR-340 was observed to enhance the proliferation, migration and invasion capacity of retinoblastoma cells. We then identified 26 DEGs from 3 retinoblastoma GEO datasets and subsequently constructed a miRNA-mRNA regulatory network. Further analysis revealed that WIF1 was a direct target of miR-340. Moreover, overexpression of WIF1 could repress retinoblastoma progression induced by miR-340 in vitro and in vivo.

Conclusion: Collectively, miR-340 functioned as an oncomiRNA to promote retinoblastoma cell proliferation, migration and invasion via regulating WIF1. Our data also provided multiple miRNAs and genes that may contribute to a better understanding of retinoblastoma pathogenesis.

Keywords: retinoblastoma, miR-340, proliferation, WIF1, invasion

\section{Introduction}

Abnormally expressed microRNAs (miRNAs) have critical roles in the cancer initiation and progression through degrading or repressing target genes posttranscriptionally. ${ }^{1,2}$ They could serve as oncogenes or tumor suppressors to regulate various biological processes, such as tumor growth, metastasis, apoptosis, stemness, autophagy and chemoresistance. ${ }^{3,4}$ Hence, understanding the molecular basis of individual miRNAs will facilitate the diagnosis and targeted therapy for cancer treatment.

miR-340 was first reported to be highly expressed in gastric cancer tissues compared with non-tumorous tissues in 2009. ${ }^{5}$ Later, however, Guled et al found that miR-340 was severely down-regulated in malignant mesothelioma. ${ }^{6}$ Recent 
studies demonstrated that miR-340 suppressed proliferation, invasion and migration in gallbladder carcinoma via targeting NT5E, inhibited metastasis by targeting EphA3 in cervical cancer and blocked proliferation and promoted apoptosis through targeting DcR3 in hepatocellular carcinoma. ${ }^{7-9}$ The above-mentioned findings suggest that miR-340 functions as a tumor suppressor in tumorigenesis. Meanwhile, other studies had shown contrary conclusions. In thyroid cancer, miR-340 was up-regulated and promoted cell proliferation by decreasing BMP4. ${ }^{10}$ miR-340 was also observed to enhance the tumor growth by reducing CCNG2 expression in gastric cancer. ${ }^{11}$ Sueta et al found that miR-340 was up-regulated in breast cancer patients with recurrence. ${ }^{12}$ Overall, the potential role of miR-340 is very complex in human cancer.

Retinoblastoma is a common malignant intraocular tumor among children. ${ }^{13}$ Although there is great improvement in the treatment strategies, the survival rate of retinoblastoma patients remains lower than $30 \%$ in some developing countries. ${ }^{14}$ Several miRNAs have been implicated in retinoblastoma, such as miR-29a, miR-98 and miR-183. ${ }^{15-17}$ However, the expression profile and function of miR-340 in retinoblastoma have not been elucidated.

Gene Expression Omnibus (GEO) is an international public repository that stores gene expression profiles from microarray and high-throughput sequencing genomics data. ${ }^{18}$ In this study, we identified many differentially expressed miRNAs (DEmiRs) and genes (DEGs) in retinoblastoma from GEO datasets and constructed a miRNA-mRNA interaction network. We confirmed that miR-340 was highly expressed in retinoblastoma tissues and cell lines, and up-regulated miR-340 correlated with poor prognosis. Furthermore, we found that miR-340 promoted retinoblastoma cell proliferation, migration and invasion through targeting WIF1.

\section{Materials and Methods}

\section{Cell Cultures and Patient Tissues}

Human retinoblastoma cell lines WERI-RB1, SO-RB50, Y79 and human retinal pigment epithelial cell line ARPE19 were purchased from ATCC and cultured in RPMI 1640 medium (Gibco, Carlsbad, CA, USA) supplemented with $10 \%$ FBS (Gibco) at $37{ }^{\circ} \mathrm{C}$ containing $5 \% \mathrm{CO}_{2}$. Fiftyeight retinoblastoma tissue samples and twelve normal retina tissues were obtained from Cangzhou Central Hospital. All of the patients were restaged according to the 8th edition of the American Joint Committee on Cancer (AJCC). The detailed clinical pathology of retinoblastoma patients was shown as Supplementary Table 1 . All protocols were approved by the institutional research committee of Cangzhou Central Hospital (NO. 20120019) and conducted in accordance with the Declaration of Helsinki. Written informed consent was obtained from each patient.

\section{Cell Transfection}

Synthesized miR-340 inhibitor, miR-340 mimics and its scrambled negative control (inhibitor NC and mimics NC), WIF1-overexpressing plasmid (pcDNA-WIF1 and pcDNA-NC) and lentiviruses containing human miR-340 (LV-miR-340 and LV-NC) were obtained from RiboBio (Guangzhou, China). Transfections were conducted using Lipofectamine 2000 (Invitrogen) according to the reagent protocol.

\section{Cell Proliferation Analysis}

Effects of miR-340 on cell proliferation were determined using cell counting kit-8 (CCK-8) assay, colony formation assay and 5-ethynyl-2'-deoxyuridine (EdU) incorporation assay. For CCK-8 assay, cells were cultured in 96-well plates at a density of $5 \times 10^{3}$ cells/well. Cell numbers were evaluated over 5 days using CCK- 8 reagent (Sigma). The absorbance at $450 \mathrm{~nm}$ was recorded using a microplate reader (BioTek). For EdU incorporation assay, cells were plated in 6-well plates. After $24 \mathrm{~h}$ incubation. Cells were treated with $50 \mathrm{mM}$ EdU solution (RiboBio) for $2 \mathrm{~h}$, fixed using 4\% paraformaldehyde, stained with DAPI (Beyotime, Shanghai, China) and photographed under an Olympus FSX100 microscope. For colony formation assay, cells were seeded in 6-well plates at a density of 500 cells/well and cultured for 2 weeks. Then, the visible colonies were fixed and stained with $0.1 \%$ crystal violet (Sigma) for $10 \mathrm{~min}$. Finally, colonies were counted under a microscope.

\section{Wound Healing and Transwell Invasion Assay}

For wound healing assay, cells were seeded in 6-well plate. Confluent cells were wounded with a $200 \mu \mathrm{L}$ pipette tip and the detached cells were gently washed twice. Images were taken from an optical microscope system at $0 \mathrm{~h}$ and $24 \mathrm{~h}$. For invasion assay, cells were seeded in the upper chamber with a Matrigel-coated membrane (BD 


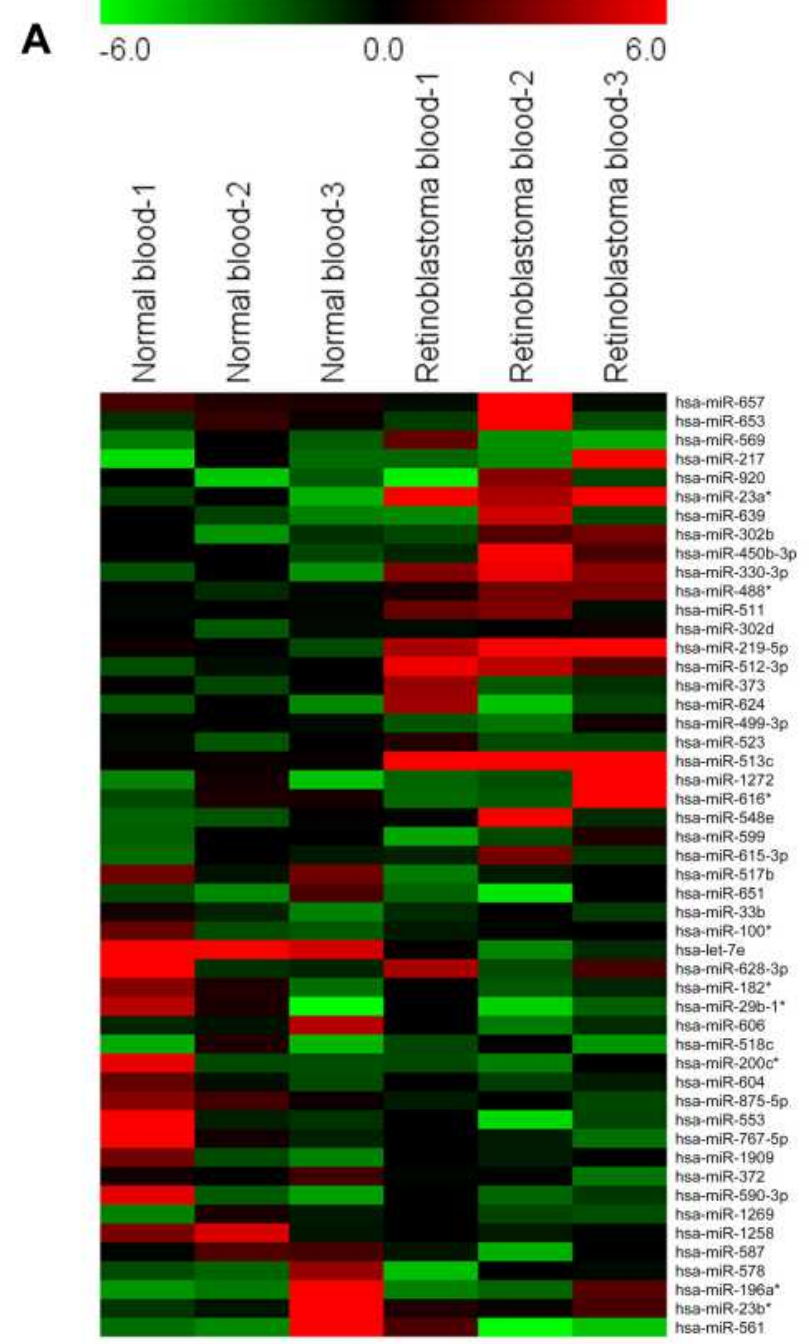

B

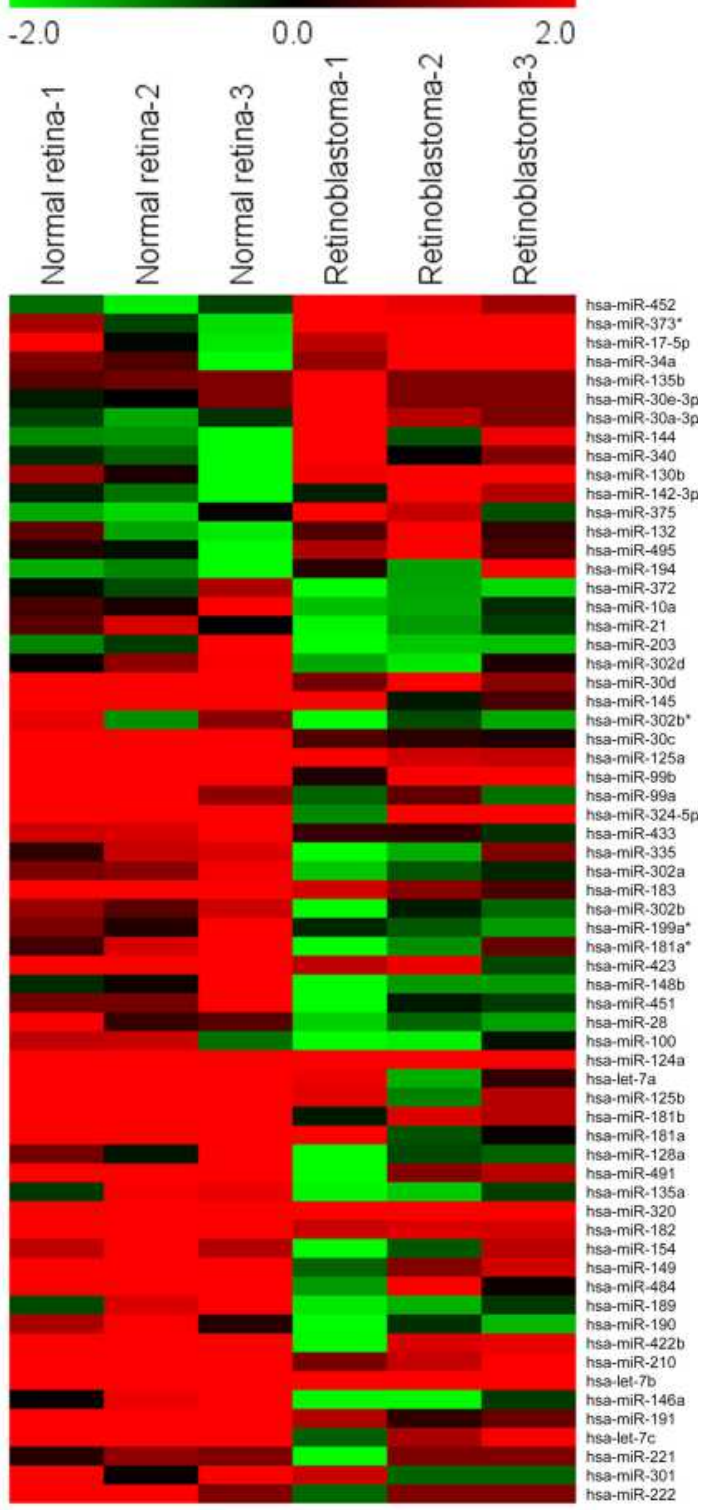

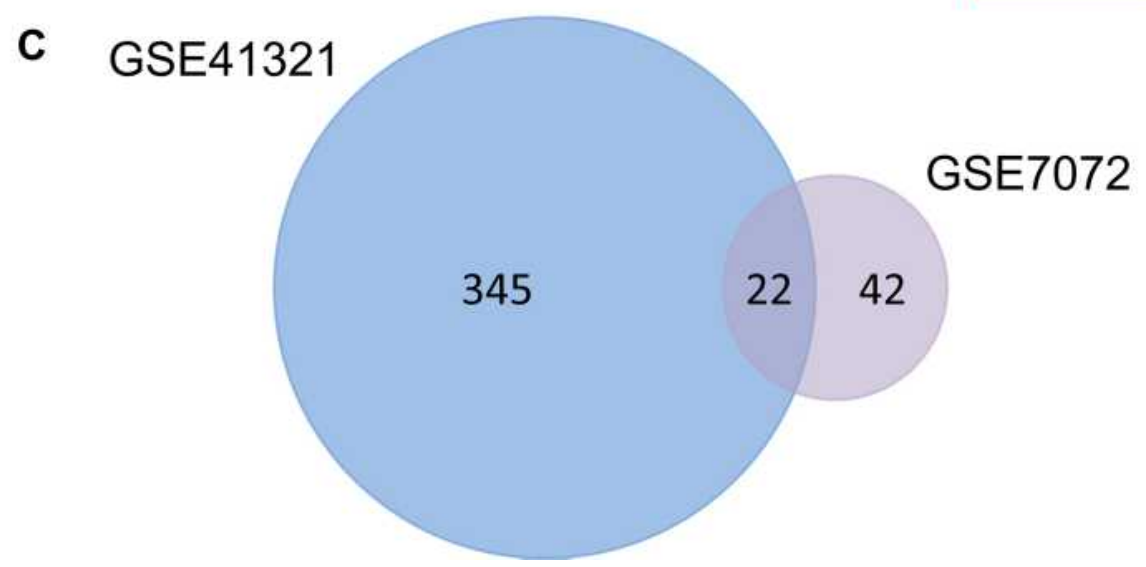

Figure I Identification of DEmiRs-associated retinoblastoma. A total of 367 and 64 DEmiRs were identified from GEO datasets GSE4I32I (3 normal whole blood serum samples and 3 retinoblastoma whole blood serum samples) and GSE7072 ( 3 human normal retina tissues and 3 human retinoblastoma tissues) using GEO2R according to the criterion: $\mathrm{P}<0.05$ and $|\log 2 \mathrm{FC}|>2$. Heat maps were generated using MeV v4.8. I. (A) Heat maps of top 25 up-regulated and 25 down-regulated miRNAs from GSE4I 32 I. (B) Heat maps of DEmiRs from GSE7072. (C) Venn diagram of overlapped DEmiRs. 
Biosciences, San Jose, CA, USA). Medium supplemented with $10 \%$ FBS was added to the lower chamber. After incubation for $24 \mathrm{~h}$, the cells migrated to the reverse side of inserts were stained with $0.1 \%$ crystal violet solution and imaged.

\section{RNA Extraction and qRT-PCR}

Total RNA was extracted by TRIzol (Invitrogen) method. cDNA was generated using the High-Capacity cDNA Reverse Transcription Kit (Applied Biosystems). qRTPCR were performed using SYBR PrimeScript RT-PCR Kit (TaKaRa) on ABI 7900HT (Applied Biosystems). The relative expression levels of miR-340 and WIF1 were calculated using $2^{-\Delta \Delta \mathrm{CT}}$ and normalized to $\mathrm{U} 6$ and $\beta$ actin, respectively. The following primer sequences were used for qRT-PCR:

\section{miR-340-Forward: 5'-TATAAAGCAATGAGACTG} AT-3',

miR-340-Reverse:

5'-GAACATGTCTGCGTAT

CTC-3',

WIF1-Forward: 5'- GGTGCCGAAATGGAGGCTT TTG-3',

WIF1-Reverse: 5'- GATGCAGAAACCAGGAGTCA CAC-3'
Table I Differentially Expressed miRNAs-Associated Retinoblastoma Identified from GEO Datasets GSE4I32I and GSE7072

\begin{tabular}{|l|l|l|l|l|}
\hline \multirow{2}{*}{ miRNA } & \multicolumn{2}{|c|}{ GSE4I32I } & \multicolumn{2}{c|}{ GSE7072 } \\
\cline { 2 - 5 } & P value & logFC & P value & logFC \\
\hline hsa-miR-144 & 0.000142 & 2.95 & 0.01368 & 2.58 \\
hsa-miR-194 & 0.009693 & 3.32 & $0.0490 I$ & 2.07 \\
hsa-miR-340 & 0.002586 & 2.19 & 0.021832 & 2.55 \\
hsa-miR-372 & 0.004067 & -7.94 & 0.0185 I4 & -2.00 \\
hsa-miR-375 & $0.007 I 5 I$ & 3.16 & 0.041457 & 2.30 \\
hsa-miR-19I & 0.007377 & -2.40 & 0.000957 & -2.85 \\
hsa-miR-99a & $0.01654 I$ & -3.00 & $0.0007 / 2$ & -3.08 \\
hsa-miR-18Ia* & 0.02208 & -2.28 & 0.029234 & -2.24 \\
hsa-miR-132 & 0.020486 & 2.27 & 0.047265 & 2.09 \\
hsa-miR-302a & 0.048405 & -4.02 & 0.006567 & -2.19 \\
hsa-miR-135b & 0.049297 & 4.43 & 0.033718 & 2.72 \\
\hline
\end{tabular}

Note: *This miRNA is not the predominantly expressed miRNA.

\section{Western Blot}

Cells were harvested and lysed in RIPA buffer (Beyotime). Proteins $(30 \mu \mathrm{g})$ were separated via 10\% SDS/PAGE gel and then transferred onto PVDF membranes (Millipore). The membranes were blocked in 5\% nonfat milk and incubated with primary antibodies targeting WIF1 (Abcam, ab155101) overnight at $4{ }^{\circ} \mathrm{C}$. Then, blots were incubated with
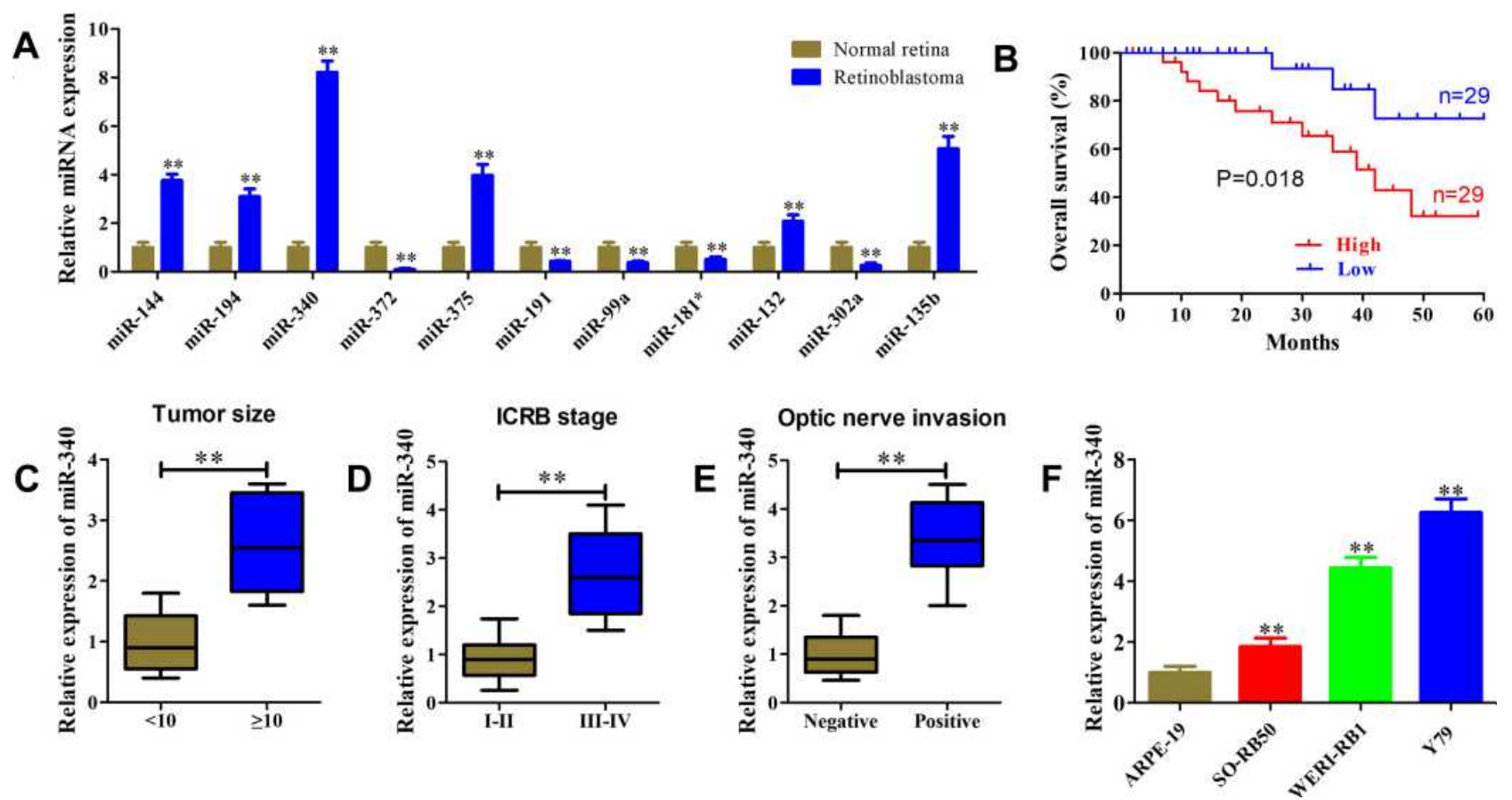

Figure 2 High miR-340 expression was correlated with retinoblastoma progression. (A) Relative expression levels of DEmiRs were determined using qRT-PCR in 58 retinoblastoma tissue samples and 12 normal retina tissues. (B) Kaplan-Meier analysis of the relationship between miR-340 expression level and overall survival of retinoblastoma patients. (C-E) miR-340 expression level was significantly up-regulated in retinoblastoma patients with large tumor size (C), advanced ICRB stage (D) and optic nerve invasion (E). (F) Relative expression level of miR-340 in retinoblastoma cell lines and normal retina cell line was determined using $q R T-P C R$. **P<0.0I. 
horseradish peroxidase-conjugated secondary antibodies and visualized using an ECL detection system (Thermo Fisher Scientific). $\beta$-actin was used as endogenous control.

\section{In vivo Xenograft Tumor Models}

BALB/c nude mice (4-6 weeks old) were purchased from Beijing Vital River Experimental Animal Technology Co, Ltd. (Beijing, China). About $1 \times 10^{7}$ LV-miR-340 and/or pcDNA-WIF1 overexpressing SO-RB50 cells were subcutaneously injected into the nude mice, respectively. The tumor volume was measured every 3 days by using digital calipers. After 4 weeks injection, mice were sacrificed and the tumors were weighted. Tumor volumes were calculated as follows: volume $=\left(\right.$ length $\times$ width $\left.^{2}\right) / 2$. All experiments were approved by the Use Committee for Animal Care and performed in accordance with the institutional guidelines of Cangzhou Central Hospital (NO. 20190452).

\section{Luciferase Reporter Assay}

microRNA.org was used to predict miR-340 binding sites on the 3'UTR of WIF1. Wild type (wt) and mutant (mut) 3'UTR of WIF1 containing miR-340 binding sites were synthesized by GenePharma (Shanghai, China) and cloned into psicheck 2 vector. Then, wt or mut luciferase vector was co-transfected with miR-340 mimics or miRNA negative control into the cells. After $48 \mathrm{~h}$ transfection, cells were harvested and the luciferase activity was detected with a Dual Luciferase Reporter Assay Kit (Promega).

\section{Bioinformatics Analysis}

miRNA profiles of retinoblastoma were obtained from GEO datasets GSE41321 and GSE7072. ${ }^{19,20}$ mRNA profiles of retinoblastoma were obtained from GEO datasets GSE97508, GSE110811 and GSE24673. ${ }^{21}$ DEmiRs or DEGs were analyzed using GEO2R according to the criteria: $\mathrm{P}<0.05$ and $|\log 2 \mathrm{FC}|>2$. Heat maps were generated using $\mathrm{MeV}$ v4.8.1. ${ }^{22}$ miRNA-mRNA interaction network was constructed using Cytoscape 3.4.0. ${ }^{23}$

\section{Statistical Analysis}

All experiments were performed in triplicate. All data were expressed as the mean \pm SD. Pearson correlation coefficient was used to assess the correlation between the expression level of miR-340 and WIF1. Kaplan-Meier method and Log rank test were used to construct survival curves. GraphPad Prism 5 software was used for all statistical analysis and $\mathrm{P}<0.05$ was considered statistically significant.

\section{Results}

\section{Identification of DEmiRs-Associated with Retinoblastoma}

To identify the DEmiRs during retinoblastoma progression, we first analyzed retinoblastoma microarrays from GEO datasets GSE41321 (3 normal whole blood serum samples and 3 retinoblastoma whole blood serum samples) and GSE7072 (3 human normal retina tissues and 3 human retinoblastoma tissues). As shown in Figure 1A and B, 367 and 64 DEmiRs were obtained from GSE41321 and GSE7072, respectively. Venn Diagram demonstrated that 22 DEmiRs were occurred in both retinoblastoma blood and tissue samples (Figure 1C). Among them, however, there were only 11 DEmiRs of whose expression levels exhibited the same pattern in the two datasets: 6 up-regulated miRNAs (miR-144, miR-194, miR-340, miR-375, miR-132 and miR-135b) and 5 down-regulated miRNAs (miR-372, miR-191, miR-99a,

Table 2 Correlation of miR-340 Expression and Clinical Parameters in Patients with Retinoblastoma

\begin{tabular}{|c|c|c|c|}
\hline \multirow{2}{*}{ Features } & \multicolumn{2}{|c|}{ miR-340 Expression } & \multirow{2}{*}{$P$ value } \\
\hline & High $(n=29)$ & Low $(n=29)$ & \\
\hline Gender & & & 0.599 \\
\hline Male & 16 & 14 & \\
\hline Female & 13 & 15 & \\
\hline Age at diagnosis & & & 0.539 \\
\hline$<5$ & 23 & 21 & \\
\hline$\geq 5$ & 6 & 8 & \\
\hline Tumor size $(\mathrm{mm})$ & & & 0.018 \\
\hline$<10$ & 9 & 18 & \\
\hline$\geq 10$ & 20 & 11 & \\
\hline Tumor laterality & & & 0.792 \\
\hline Unilateral & 16 & 15 & \\
\hline Bilateral & 13 & 14 & \\
\hline Differentiation grade & & & 0.256 \\
\hline Well/moderately & 22 & 18 & \\
\hline Poorly & 7 & II & \\
\hline ICRB stage & & & 0.036 \\
\hline I-II & 10 & 18 & \\
\hline III-IV & 19 & 11 & \\
\hline Optic nerve invasion & & & 0.008 \\
\hline Positive & 21 & II & \\
\hline Negative & 8 & 18 & \\
\hline
\end{tabular}

Note: $\chi^{2}$ test was used.

Abbreviation: ICRB, the international classification of retinoblastoma. 
miR-181a* and miR-302a) in retinoblastoma samples compared with normal controls (Table 1).

\section{High miR-340 Expression Was Correlated with Retinoblastoma Progression}

Next, we validated the expression levels of DEmiRs using our enrolled tissues. As shown in Figure 2A, miR-340 was the most highly expressed miRNA in retinoblastoma tissues in comparison with normal retina tissues. As miR-340 has not been reported in retinoblastoma, we selected miR340 for further analysis in this study. Kaplan-Meier analysis demonstrated that higher miR-340 expression was significantly associated with worse overall survival of retinoblastoma patients (Figure 2B, $\mathrm{P}=0.018$ ). We observed that miR-340 expression was positively correlated with large tumor size (Figure 2C), advanced ICRB
A
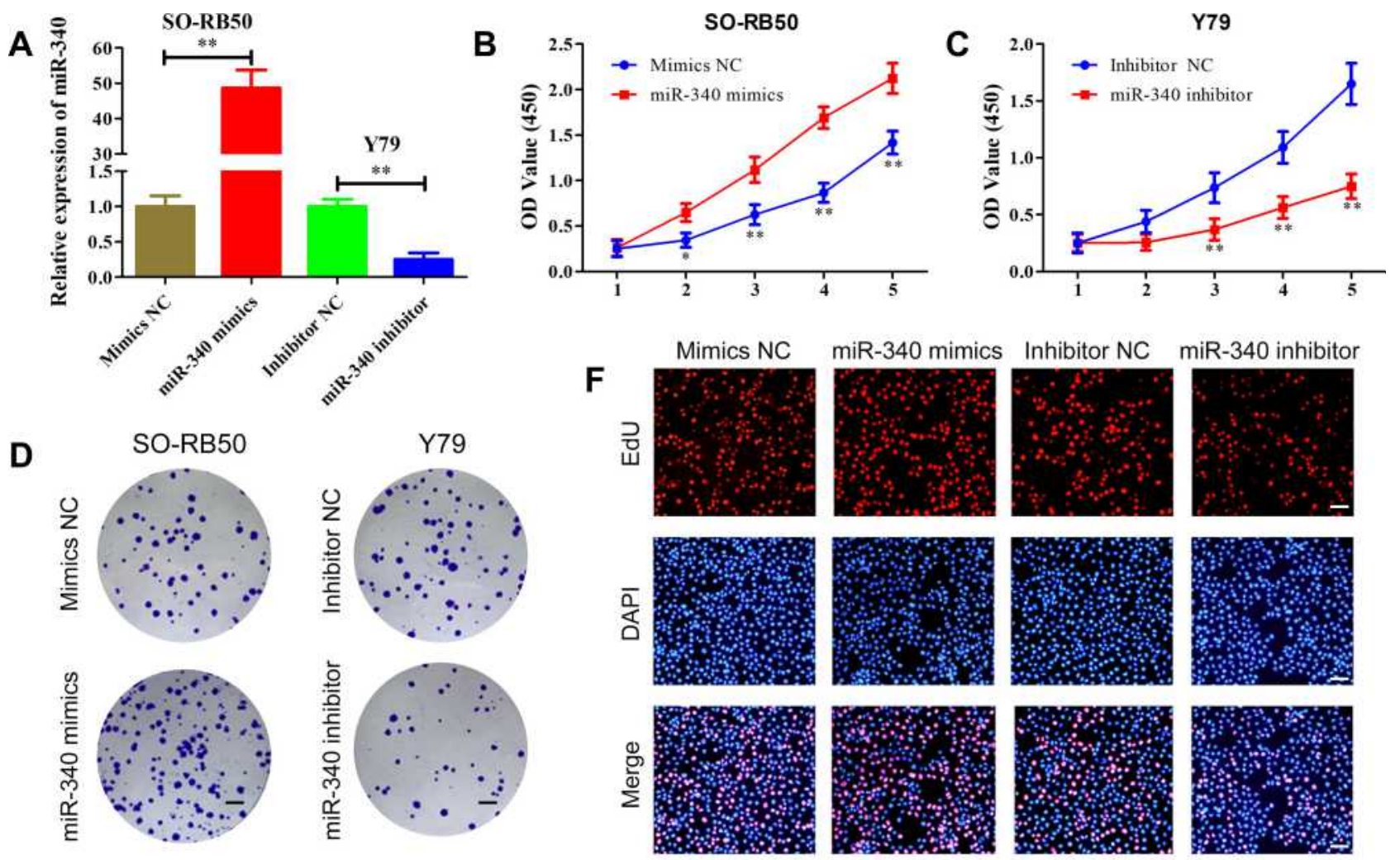

SO-RB50

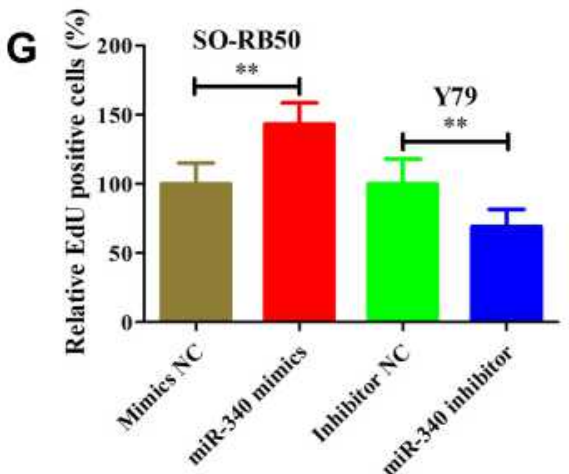

Figure 3 miR-340 promoted retinoblastoma cell proliferation in vitro. (A) miR-340 expression level was determined using qRT-PCR in WERI-RBIand Y79 cells after transfection with miR-340 mimics or miR-340 inhibitor. (B and C) CCK-8 assay results showed that miR-340 mimics promoted SO-RB50 cells proliferation (B), while miR340 inhibitor suppressed Y79 cells proliferation (C) compared with negative control. (D and E) Colony formation assay results showed that miR-340 overexpression increased the number of colonies in SO-RB50 cells (D), but miR-340 knockdown decreased the number of colonies in Y79 cells (E) compared with negative control. (F and G) EdU incorporation assay demonstrated that up-regulation of miR-340 dramatically enhanced the percentage of EdU-positive cells in SO-RB50 cells (F) and downregulation of miR-340 reduced the percentage of EdU-positive cells in Y79 cells $(\mathbf{G})$ with negative control. $* \mathrm{P}<0.05, * * \mathrm{P}<0.01$. Scale bars, $100 \mu \mathrm{m}$. 
stage (Figure 2D) and optic nerve invasion (Figure 2E). Consistently, the correlation between miR-340 expression and pathological features was further confirmed by the univariate $\chi^{2}$ test (Table 2). qRT-PCR results also showed that miR-340 was up-regulated 1.85-fold, 4.43-fold and 6.26-fold in retinoblastoma cell lines SO-RB50, WERI$\mathrm{RB} 1$ and Y79 compared with that of normal retina cell line ARPE-19, respectively (Figure $2 \mathrm{~F}$ ).

\section{miR-340 Promoted Retinoblastoma Cell Proliferation in vitro}

To determine the biological function of miR-340, gain-offunction and loss-of-function assays were performed by transfecting miR-340 mimics or miR-340 inhibitor into SO-RB50 and Y79 cells, respectively. The up-regulated and down-regulated expression levels of miR-340 were confirmed by qRT-PCR (Figure 3A). We applied CCK-8 assay to evaluate the effects of miR-340 on cell proliferation. Results showed that ectopic expression of miR-340 significantly increased the proliferative capacity in SORB50 cells, whereas silencing of miR-340 with its specific inhibitor substantially inhibited the growth of Y79 cells
(Figure 3B and C). Consistent with CCK-8 assay results, we observed a higher colony numbers of SO-RB50 cells after miR-340 overexpression compared with negative control, and vice versa in Y79 cells (Figure 3D and E). Additionally, EdU incorporation assay demonstrated that up-regulation of miR-340 dramatically enhanced the percentage of EdU-positive cells and down-regulation of miR-340 led to the opposite effect (Figure $3 \mathrm{~F}$ and $\mathrm{G}$ ). These results indicate that $\mathrm{miR}-340$ could promote retinoblastoma cell proliferation.

\section{miR-340 Enhances the Migration and Invasion Capacity of Retinoblastoma Cells}

Because there was a strong association between miR-340 and retinoblastoma invasion in clinical samples, we explored the effects of miR-340 on retinoblastoma metastasis using wound healing assays and transwell invasion assays. As shown in Figure $4 \mathrm{~A}$ and $\mathrm{B}$, ectopic expression of miR-340 promoted the SO-RB50 cells to close the gap in a wound healing assay in comparison with negative group. However, the ability to close the gap was suppressed by miR-340 knockdown in Y79 cells. Moreover,
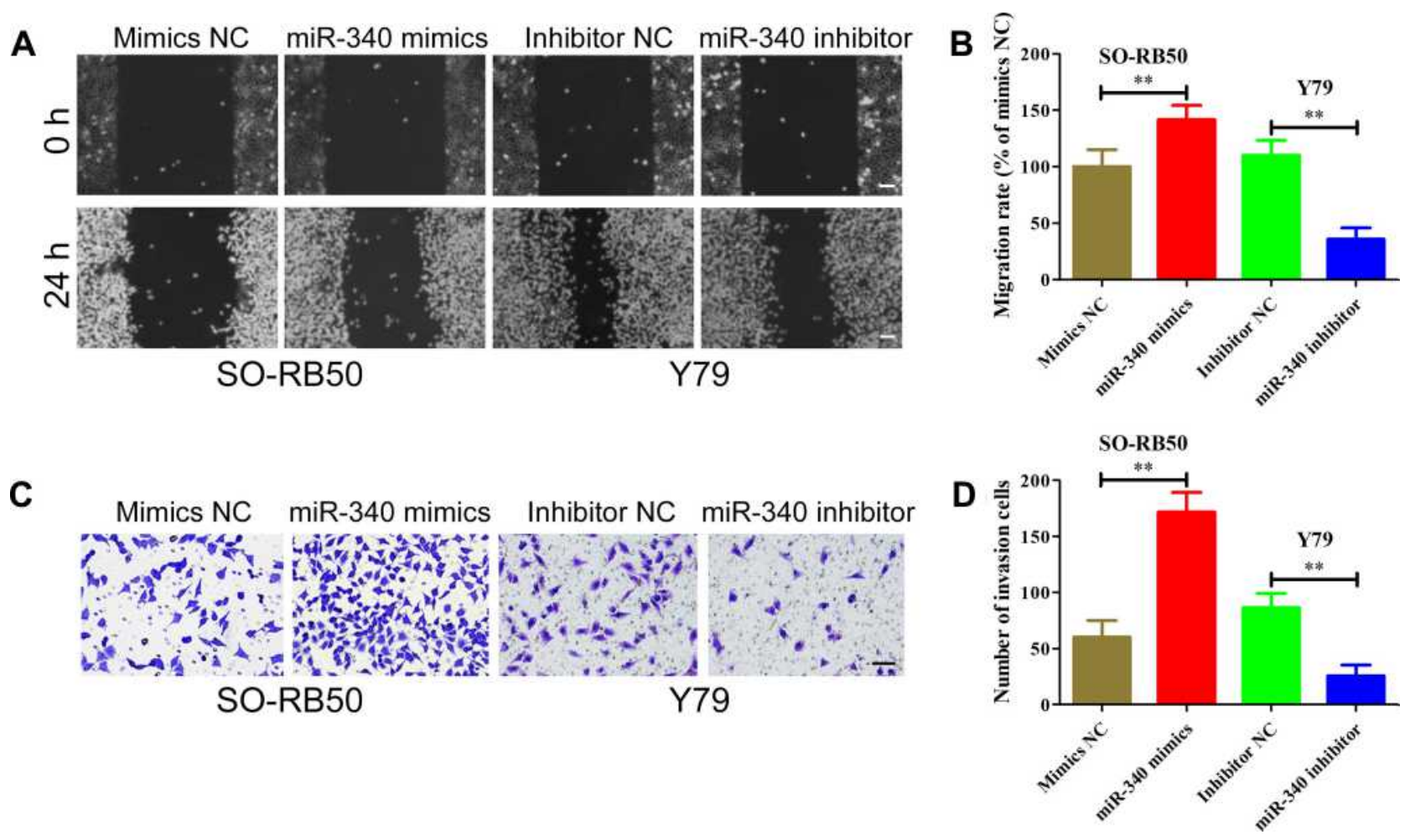

Figure 4 miR-340 enhances the migration and invasion capacity of retinoblastoma cells. (A and B) Wound healing assays results showed that miR-340 mimics promoted migration of SO-RB50 cells, while miR-340 inhibitor suppressed migration of Y79 cells compared with negative control. (C and D) Transwell invasion assays results showed that miR-340 overexpression increased the number of invasive SO-RB50 cells, but miR-340 knockdown decreased the number of invasive Y79 cells compared with negative control. **P $<0.01$. Scale bars, $100 \mu \mathrm{m}$. 
the transwell invasion assays showed more SO-RB50 cells penetrating the membrane of chambers after transfecting with miR-340 mimics than that of miRNA NC (Figure 4C and D). An inversed phenotypic alteration was observed in Y79 cells after miR-340 knockdown. These findings suggest that miR-340 also play a crucial role in retinoblastoma metastasis.

\section{Identification of DEGs-Associated with Retinoblastoma}

A miRNA always exerts biological roles through interacting with its target genes. To explore downstream target genes of miR-340, we analyzed the DEGs from retinoblastoma GEO datasets GSE24673 (2 human normal retina tissues and 3 human retinoblastoma tissues), GSE97508 (3) human normal retina tissues and 6 human retinoblastoma tissues) and GSE110811 (3 human normal retina tissues and 28 human retinoblastoma tissues). We identified 487, 1918 and 39 DEGs, respectively (Figure $5 \mathrm{~A}-\mathrm{C}$ ). A total of 26 genes were commonly occurred in the 3 datasets (Figure 5D). Among the 26 genes, 4 genes were up-regulated and 22 genes were down-regulated (Table 3).

\section{miR-340 Directly Targets WIFI}

To further analyze the regulatory relationships between the DEmiRs and DEGs, we constructed a miRNA-mRNA network based on their expression levels and target interaction predicted using microRNA.org (Figure 6A). miR-340 was the common miRNA for 9 genes (CNGA1, YPEL2, PCDH15, FRZB, BBS9, BCO2, MBNL2, WIF1 and IMPG1) were predicted to contain putative-binding sites of miR-340.
A

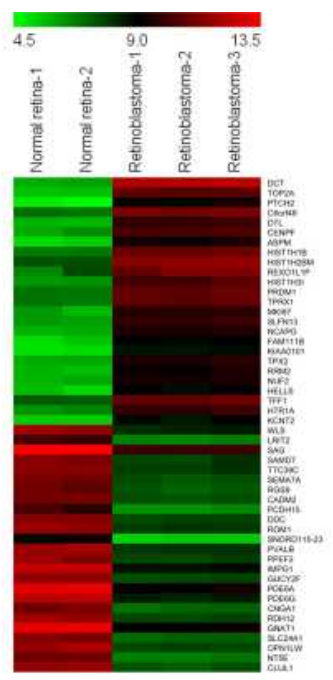

B

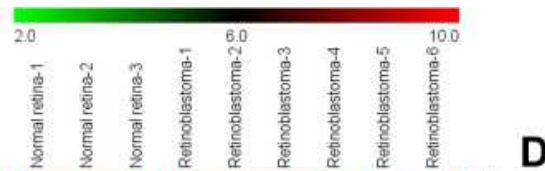

D

\section{GSE24673}

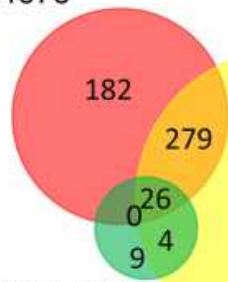

1600

GSE97508

GSE110811

\section{C}

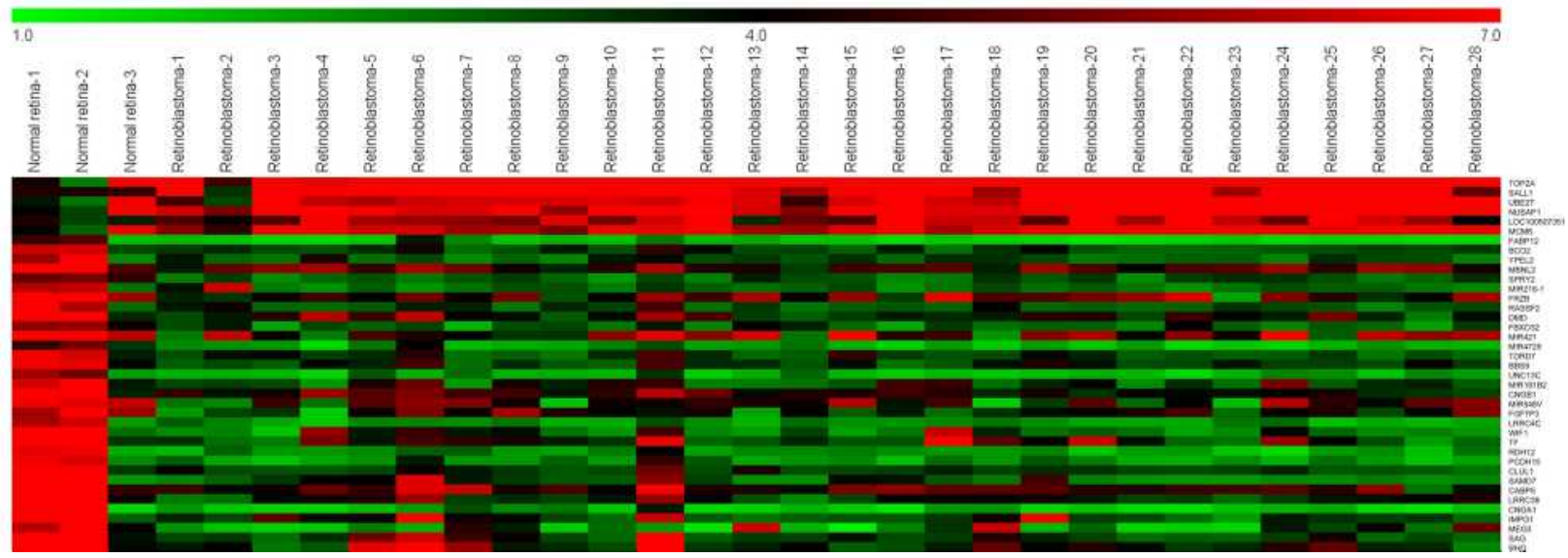

Figure 5 Identification of DEGs-associated with retinoblastoma. A total of 487, 1918 and 39 DEGs were obtained from GEO datasets GSE24673 (2 human normal retina tissues and 3 human retinoblastoma tissues), GSE97508 ( 3 human normal retina tissues and 6 human retinoblastoma tissues) and GSEI I08II ( 3 human normal retina tissues and 28 human retinoblastoma tissues) using GEO2R according to the criterion: $\mathrm{P}<0.05$ and $|\log 2 \mathrm{FC}|>2$. Heat maps were generated using MeV v4.8. I. (A) Heat maps of top 25 up-regulated and 25 down-regulated genes from GSE24673. (B) Heat maps of top 25 up-regulated and 25 down-regulated genes from GSE97508. (C) Heat maps of DEGs from GSEI I08II. (D) Venn diagram of overlapped DEGs. 
Table 3 Expression Level of 26 Retinoblastoma-Associated DEGs in GEO Datasets GSE24673, GSE97508 and GSEI I08I I

\begin{tabular}{|c|c|c|c|c|c|c|}
\hline \multirow[t]{2}{*}{ Gene } & \multicolumn{2}{|c|}{ GSE24673 } & \multicolumn{2}{|c|}{ GSE97508 } & \multicolumn{2}{|c|}{ GSEII08II } \\
\hline & $P$ value & $\log F C$ & $P$ value & $\log F C$ & $P$ value & $\log F C$ \\
\hline CNGAI & $2.89 \mathrm{E}-08$ & -3.92 & $2.44 \mathrm{E}-10$ & -7.30 & I.14E-06 & -3.38 \\
\hline RHO & $1.58 \mathrm{E}-08$ & -3.37 & 2.15E-09 & -7.79 & $9.02 \mathrm{E}-05$ & -4.65 \\
\hline CABP5 & I.IE-07 & -2.67 & 8.9IE-08 & -4.24 & $8.53 \mathrm{E}-05$ & -2.94 \\
\hline RASSF2 & $3.47 \mathrm{E}-08$ & -2.89 & I.76E-06 & -5.98 & 4.44E-05 & -2.16 \\
\hline CNGBI & $9.12 \mathrm{E}-09$ & -3.42 & $2.05 \mathrm{E}-06$ & -3.38 & 0.000114 & -2.54 \\
\hline CLULI & $5.16 \mathrm{E}-09$ & -4.28 & 3.37E-06 & -5.57 & $6.93 \mathrm{E}-07$ & -2.92 \\
\hline NUSAPI & $2.09 \mathrm{E}-07$ & 2.53 & $3.48 \mathrm{E}-06$ & 3.61 & $7.75 \mathrm{E}-05$ & 2.12 \\
\hline TOP2A & $5.75 \mathrm{E}-10$ & 5.1 & $3.65 \mathrm{E}-06$ & 6.79 & 0.000112 & 2.89 \\
\hline SAG & $6.54 \mathrm{E}-09$ & -3.46 & $3.74 \mathrm{E}-06$ & -5.98 & $6.16 \mathrm{E}-06$ & -4.55 \\
\hline YPEL2 & 8.87E-08 & -3.33 & $6.56 \mathrm{E}-06$ & -4.22 & $8.83 \mathrm{E}-05$ & -2.09 \\
\hline FABPI 2 & I.58E-08 & -3.1 & 0.000105 & -3.04 & $4.5 \mathrm{E}-06$ & -2.07 \\
\hline $\mathrm{FBXO} 32$ & I.4E-07 & -2.62 & 0.000114 & -2.77 & 2.17E-07 & -2.28 \\
\hline PCDHI5 & 3.19E-07 & -3.57 & 0.000421 & -3.15 & $2.26 \mathrm{E}-06$ & -2.88 \\
\hline FRZB & $3.38 \mathrm{E}-08$ & -3.21 & 0.000565 & -5.19 & 0.00184 & -2.16 \\
\hline BBS9 & I.9E-07 & -2.96 & 0.000707 & -3.11 & $1.18 \mathrm{E}-06$ & -2.43 \\
\hline SAMD7 & 4. I 4E-07 & -3.47 & 0.00086 & -3.27 & $0.0006 \mathrm{I}$ & -2.93 \\
\hline MCM6 & I.0IE-07 & 2.71 & 0.000881 & 2.69 & 0.000258 & 2.06 \\
\hline UBE2T & I.34E-07 & 2.62 & 0.000983 & 3.24 & 0.00149 & 2.24 \\
\hline $\mathrm{BCO} 2$ & $5.78 \mathrm{E}-07$ & -3.18 & 0.0015 & -2.03 & $6.33 \mathrm{E}-06$ & -2.08 \\
\hline LRRC39 & $2.78 \mathrm{E}-06$ & -3.14 & 0.00165 & -4.42 & 4.7IE-06 & -2.95 \\
\hline TDRD7 & $2.08 \mathrm{E}-08$ & -2.98 & 0.00209 & -3.94 & $3.28 \mathrm{E}-06$ & -2.39 \\
\hline MBNL2 & I.I4E-06 & -2.38 & 0.00323 & -4.27 & 0.000265 & -2.11 \\
\hline $\mathrm{RDH} / 2$ & 6.59E-09 & -3.97 & 0.00385 & -4.25 & I.74E-06 & -2.87 \\
\hline WIFI & I.5E-07 & -2.88 & 0.00659 & -5.60 & 0.00077 & -2.72 \\
\hline IMPGI & $3.6 \mathrm{E}-09$ & -3.79 & 0.0123 & -5.09 & 0.00034 & -3.48 \\
\hline UNCI3C & $3.02 \mathrm{E}-06$ & -2.33 & 2.29E-07 & -4.91 & $6.29 \mathrm{E}-07$ & -2.44 \\
\hline
\end{tabular}

Next, we applied qRT-PCR to evaluate the influence of miR340 on the expression levels of candidate genes. As shown in Figure 6B, WIF1 expression level was the most affected after miR-340 overexpression or knockdown in SO-RB50 and Y79 cells, respectively. These results indicate that WIF1 was the most candidate downstream target of miR-340.

Subsequently, we constructed wt-WIF1 3 'UTR and mut-WIF1 3'UTR reporter vectors that contained putativebinding sites to confirm the direct interaction between miR-340 and WIF1 3'UTR (Figure 6C). Luciferase reporter assays showed miR-340 mimics transfection resulted in a reduction of about $32 \%$ and $25 \%$ luciferase activity in WERI-RB1 and Y79 cells transfected with wt vector, but not mut vector (Figure 6D and 6E). We also observed a significant decrease of WIF1 expression in retinoblastoma tissues and cell lines (Figure 6F and G). Furthermore, Pearson correlation analysis revealed that miR-340 level in retinoblastoma tissues was inversely associated with WIF1 level (Figure 6H; r=-0.7224, $\mathrm{P}<0.0001$ ). Taken together, our data imply that WIF1 is a direct target of miR-340 in retinoblastoma.

\section{Overexpression of WIFI Represses Retinoblastoma Progression Induced by miR-340 in vitro and in vivo}

To confirm whether miR-340 promoted retinoblastoma cell proliferation, migration and invasion through regulating WIF1, miR-340 mimics or mimics $\mathrm{NC}$ and pcDNAWIF1 or pcDNA-NC were co-transfected into SO-RB50 cells. Firstly, Western blot analysis was performed to validate WIF1 overexpression (Figure 7A). CCK-8 assay, colony formation assay and EdU incorporation assay results showed that miR-340 mimics suppressed cell proliferation. However, miR-340 mimics and pcDNA-WIF1 co-transfection significantly inhibited cell proliferation compared with miR-340 mimics and pcDNA-NC co- 
A

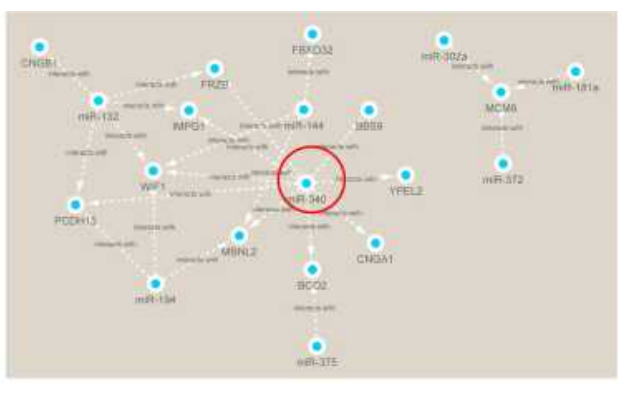

B

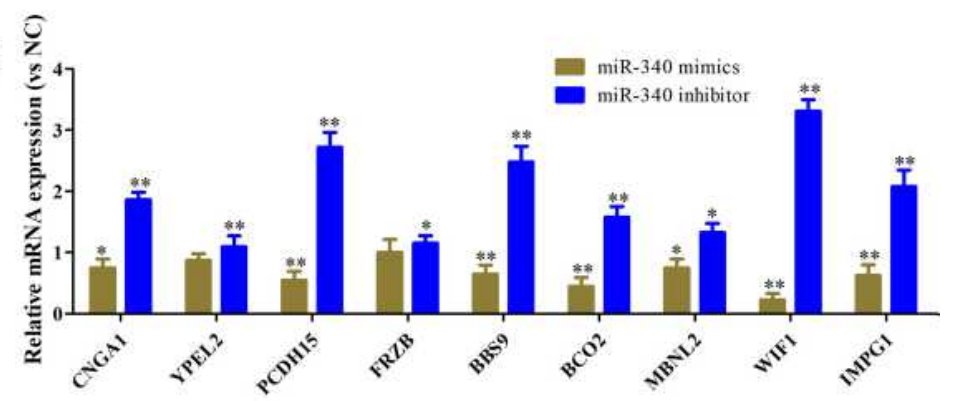

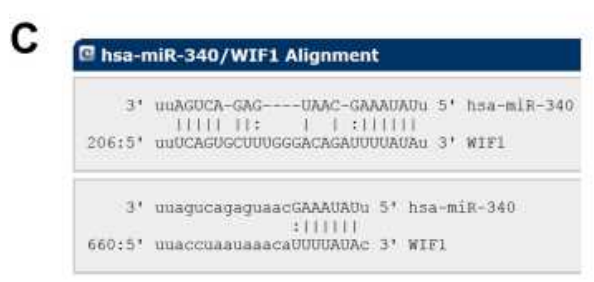

D
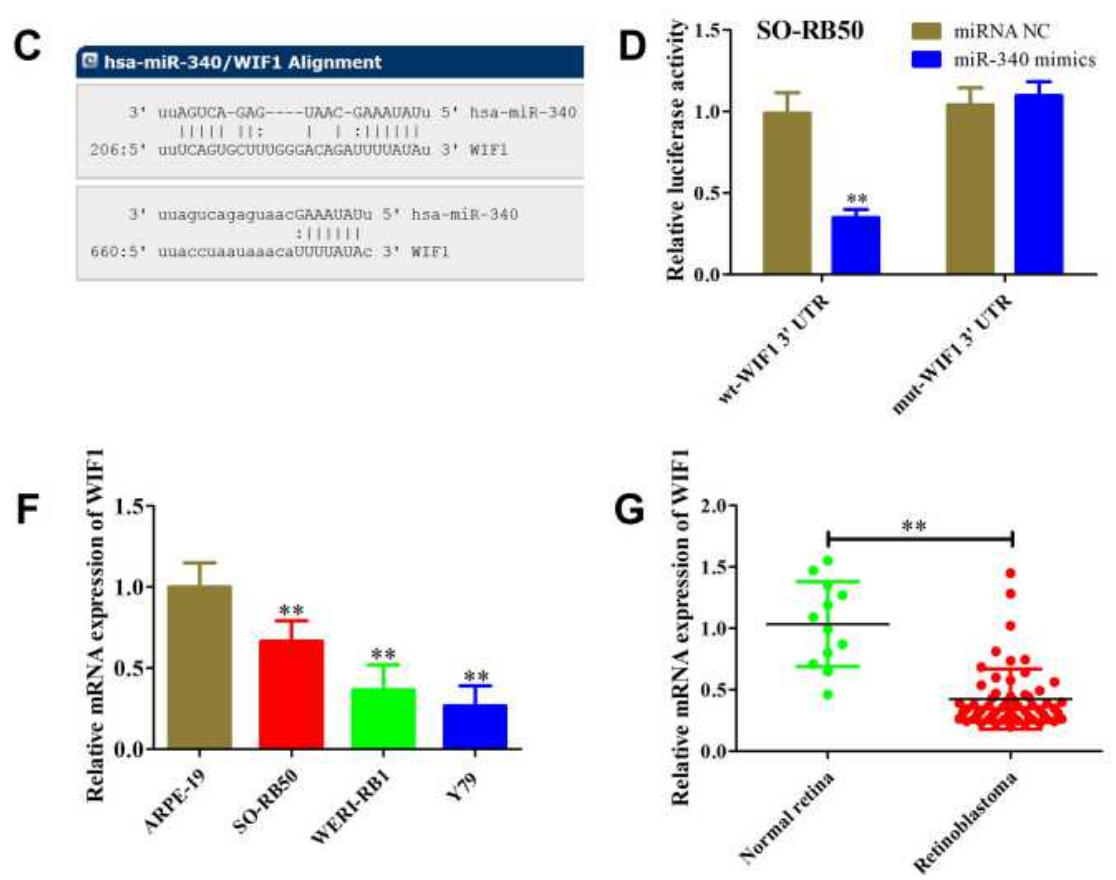
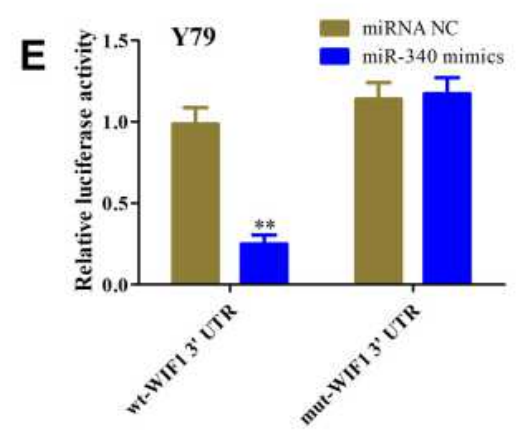

H

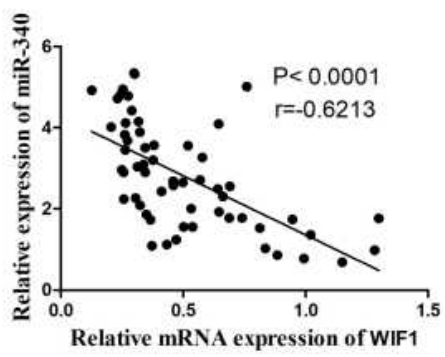

Figure 6 miR-340 directly targets WIFI. (A) miRNA-mRNA network analysis. The regulatory relationship of miRNAs and genes was predicted using microRNA.org and then visualized using Cytoscape 3.4.0. This network contained II miRNAs and 26 genes. (B) Relative expression levels of 9 candidate target genes of miR-340 in WERI-RB I after miR-340 overexpression or Y79 cells after miR-340 suppression. (C) The 3'UTR of WIFI contained two binding sites of miR-340 predicted using microRNA.org. (D and E) Luciferase activity was measured in WERI-RBI (D) and Y79 (E) cells co-transfected with miR-340 mimics or miRNA negative and wild type (wt) or mutant (mut) $3^{\prime}$ UTR of WIFI. (F) qRT-PCR results showed that WIFI mRNA expression level in retinoblastoma cell lines was significantly down-regulated compared with retinal pigment epithelial cell line ARPE-19. (G) qRT-PCR results showed that WIFI mRNA expression level in retinoblastoma tissues was lower than normal retina tissues. (H) Pearson correlation analysis between miR-340 and WIFI. $* \mathrm{P}<0.05, * * \mathrm{P}<0.01$.

transfection (Figure 7B-D). Besides, up-regulation of WIF1 also reversed the promotion of miR-340 overexpression-induced cell migration and invasion in SO-RB50 cells (Figure 7E and F).

Finally, we performed an in vivo tumor growth experiment by subcutaneously injecting SO-RB50 cells stably LV-miR-340 and/or pcDNA-WIF1 into nude mice. Consistent with the in vitro findings, ectopic expression of miR-340 significantly promoted tumor growth compared with negative control group (Figure 7G-I). Meanwhile, WIF1 overexpression eliminated the promotion impact of miR-340 on tumor growth. Altogether, these data support the idea that miR-340 promotes retinoblastoma progression by inhibiting WIF1 expression.

\section{Discussion}

Previous studies indicated that miR-340 exerted important biological roles in several human cancers, yet its function in retinoblastoma progression remains unclear. ${ }^{5-12}$ As mentioned above, miR-340 is suggested to play a complex role in tumorigenesis.

At present study, we identified 11 dysregulated miRNAs from GEO datasets, including miR-340. miR340 expression level was confirmed to be up-regulated in 

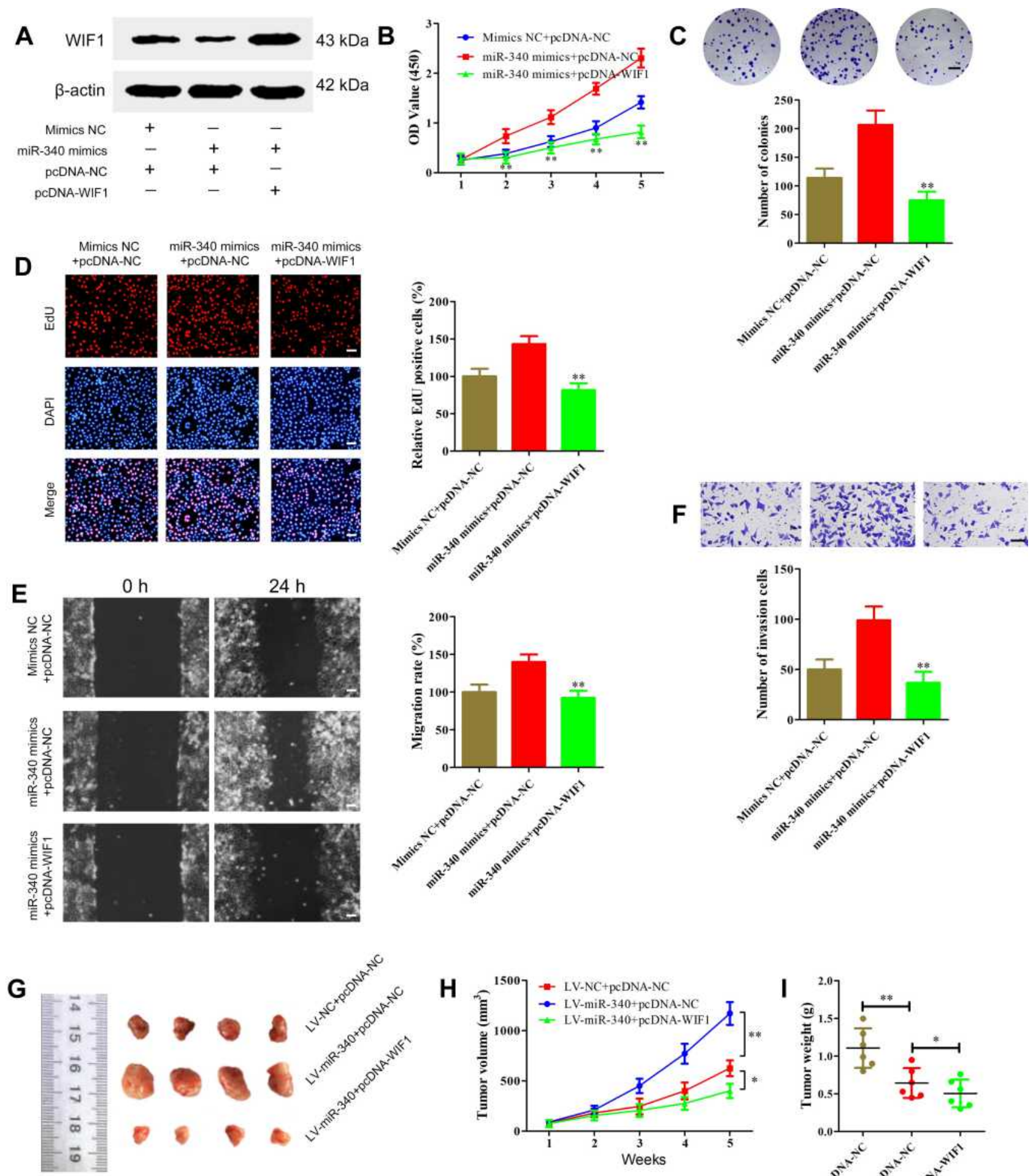

Figure 7 Overexpression of WIFI represses retinoblastoma progression induced by miR-340 in vitro and in vivo. (A) WIFI expression level was determined using Western blot in SO-RB50 cells transfected with pcDNA-WIFI or pcDNA-NC. (B-D) CCK-8 assay (B), colony formation assay (C) and EdU incorporation assay results showed that co-transfection of miR-340 mimics and pcDNA-WIFI inhibited cell proliferation compared with co-transfection of miR-340 mimics and pcDNA-NC in SO-RB50 cells. (E and F) Wound healing assays (E) and transwell invasion assays (F) up-regulation of WIFI also reversed the promotion of miR-340 overexpression-induced cell migration and invasion in SO-RB50 cells. (G-I) About I $\times 10^{7}$ LV-miR-340 and/or PcDNA-WIFI overexpressing SO-RB50 cells were subcutaneously injected into the nude mice respectively $(\mathrm{n}=6)$. After 4 weeks injection, mice were sacrificed and the tumors were weighted. (G) Representative images of surgically dissected tumors. (H) Tumor growth. (I) Tumor weight. $* \mathrm{P}<0.05$, $* * \mathrm{P}<0.01$. Scale bars, $100 \mu \mathrm{m}$. 
retinoblastoma tissues and cell lines. Clinicopathological features illustrated that high level of miR-340 was positively associated with retinoblastoma progression. Functionally, we observed that miR-340 promoted retinoblastoma cell proliferation and metastasis. These findings strongly imply that miR-340 functions as an oncogene in retinoblastoma pathogenesis.

WIF1, a Wnt pathway inhibitor, is a classical tumor suppressor deregulated in various tumors. Previous studies demonstrated that WIF1 was involved in multiple biological processes, including tumor growth, metastasis, cell cycle, apoptosis and stemness. ${ }^{24-28}$ Frequent promoter hypermethylation of WIF1 was always associated with unfavorable prognosis in multiple human tumors. ${ }^{29-33}$ In addition, several non-coding RNAs were also reported to regulate WIF1 expression at transcriptional level, including HOXC6, HOTAIR, miR-181a, miR-552, miR-590-3p and miR-603. ${ }^{34-39}$ Based on bioinformatics analysis and mechanism investigations, WIF1 was verified to be responsible for miR-340-mediated accelerated proliferation and metastasis. According to miRNA-mRNA regulatory network, miR-194, miR-144 and miR-132 were also suggested to be candidate miRNAs that can directly target WIF1. Thus, our present study enriches our understanding of WIF1 regulation in the tumorigenesis and progression.

Integrative analysis of GEO datasets also identified several abnormally expressed genes, such as TOP2A, UBE2T, RASSF2 and NUSAP1. Recent studies indicated that high expression level of TOP2A was associated with poor prognosis. ${ }^{40-43}$ UBE2T acts as an oncogenic driver in several types of cancers, including hepatocellular carcinoma, gastric cancer, osteosarcoma, nasopharyngeal carcinoma and prostate cancer. ${ }^{44-48}$ Similar to WIF1, RASSF2 was frequently methylated inactivation and decreased RASSF2 was closely related to shorter survival. ${ }^{49-51}$ NUSAP1 could promote invasion and migration in cervical carcinoma, colorectal cancer and prostate cancer. ${ }^{52-54}$ These findings indicate that these dysregulated genes may also affect the development and progression of retinoblastoma. To date, however, their functional roles and clinical significance in retinoblastoma have not been established yet. Further studies of these identified genes will help to elucidate the new mechanisms underlying retinoblastoma pathogenesis.

\section{Conclusion}

To conclude, miR-340 acts as an oncogenic role in retinoblastoma to facilitate tumor growth and metastasis via regulating WIF1. More importantly, this integrated analysis of GEO datasets identified several useful biomarkers and potential therapeutic targets for retinoblastoma, which might be worthy for further investigations.

\section{Disclosure}

The authors declare no competing financial interests of this article.

\section{References}

1. Garzon R, Fabbri M, Cimmino A, et al. MicroRNA expression and function in cancer. Trends Mol Med. 2006;12(12):580-587. doi:10.1016/j.molmed.2006.10.006

2. Gregory RI, Shiekhattar R. MicroRNA biogenesis and cancer. Cancer Res. 2005;65(9):3509-3512. doi:10.1158/0008-5472.CAN-05-0298

3. Chen CZ. MicroRNAs as oncogenes and tumor suppressors. $N$ Engl $J$ Med. 2005;353(17):1768-1771. doi:10.1056/NEJMp058190

4. Shenouda SK, Alahari SK. MicroRNA function in cancer: oncogene or a tumor suppressor? Cancer Metastasis Rev. 2009;28(3-4):369-378. doi:10.1007/s10555-009-9188-5

5. Guo J, Miao Y, Xiao B, et al. Differential expression of microRNA species in human gastric cancer versus non-tumorous tissues. $J$ Gastroenterol Hepatol. 2009;24(4):652-657. doi:10.1111/j.14401746.2008.05666.x

6. Guled M, Lahti L, Lindholm PM, et al. CDKN2A, NF2, and JUN are dysregulated among other genes by miRNAs in malignant mesothelioma -A miRNA microarray analysis. Genes Chromosomes Cancer. 2009;48(7):615-623. doi:10.1002/gcc.20669

7. Wang N, Xiang X, Chen K, et al. Targeting of NT5E by miR-30b and miR-340 attenuates proliferation, invasion and migration of gallbladder carcinoma. Biochimie. 2018;146:56-67. doi:10.1016/j. biochi.2017.10.027

8. Xiao H, Yu L, Li F, et al. MiR-340 suppresses the metastasis by targeting EphA3 in cervical cancer. Cell Biol Int. 2018;42 (9):1115-1123. doi:10.1002/cbin.10974

9. Xie L, Chen Z, Liu H, et al. Effects of miR-340 on hepatocellular carcinoma by targeting the DcR3 gene. Dig Liver Dis. 2018;50 (3):291-296. doi:10.1016/j.dld.2017.10.024

10. Zhao P, Ma W, Hu Z, et al. Up-regulation of miR-340-5p promotes progression of thyroid cancer by inhibiting BMP4. $J$ Endocrinol Invest. 2018;41(10):1165-1172. doi:10.1007/s40618-018-0848-6

11. Yin G, Zhou H, Xue Y, et al. MicroRNA-340 promotes the tumor growth of human gastric cancer by inhibiting cyclin G2. Oncol Rep. 2016;36(2):1111-1118. doi:10.3892/or.2016.4876

12. Sueta A, Yamamoto Y, Tomiguchi M, et al. Differential expression of exosomal miRNAs between breast cancer patients with and without recurrence. Oncotarget. 2017;8(41):69934-69944. doi:10.18632/ oncotarget. 19482

13. Al-Nawaiseh I, Jammal HM, Khader YS, et al. Retinoblastoma in Jordan, 2003-2013: ocular survival and associated factors. Ophthalmic Epidemiol. 2014;21(6):406-411. doi:10.3109/09286586.2014.967781

14. Singh G, Daniels AB. Disparities in retinoblastoma presentation, treatment, and outcomes in developed and less-developed countries. Semin Ophthalmol. 2016;31(4):310-316. doi:10.3109/ 08820538.2016.1154177

15. Liu S, Zhang X, Hu C, et al. miR-29a inhibits human retinoblastoma progression by targeting STAT3. Oncol Rep. 2018;39(2):739-746. doi:10.3892/or.2017.6144

16. Guo L, Bai Y, Ji S, et al. MicroRNA-98 suppresses cell growth and invasion of retinoblastoma via targeting the IGF1R/k-Ras/Raf/MEK/ ERK signaling pathway. Int $J$ Oncol. 2019;54(3):807-820. doi:10.3892/ijo.2019.4689 
17. Wang J, Wang X, Li Z, et al. MicroRNA-183 suppresses retinoblastoma cell growth, invasion and migration by targeting LRP6. FEBS J. 2014;281(5):1355-1365. doi:10.1111/febs.12659

18. Barrett T, Wilhite SE, Ledoux P, et al. NCBI GEO: archive for functional genomics data sets-update. Nucleic Acids Res. 2013;41: D991-995. doi:10.1093/nar/gks1193

19. Beta M, Venkatesan N, Vasudevan M, et al. Identification and insilico analysis of retinoblastoma serum microRNA profile and gene targets towards prediction of novel serum biomarkers. Bioinform Biol Insights. 2013;7:21-34. doi:10.4137/BBI.S10501

20. Huang JC, Babak T, Corson TW, et al. Using expression profiling data to identify human microRNA targets. Nat Methods. 2007;4 (12):1045-1049. doi:10.1038/nmeth1130

21. Hudson LE, Mendoza P, Hudson WH, et al. Distinct gene expression profiles define anaplastic grade in retinoblastoma. Am J Pathol. 2018;188(10):2328-2338. doi:10.1016/j.ajpath.2018.06.013

22. Saeed AI, Sharov V, White J, et al. TM4: a free, open-source system for microarray data management and analysis. Biotechniques. 2003;34(2):374-378. doi:10.2144/03342mt01

23. Shannon P, Markiel A, Ozier O, et al. Cytoscape: a software environment for integrated models of biomolecular interaction networks. Genome Res. 2003;13(11):2498-2504. doi:10.1101/ gr. 1239303

24. Ramachandran I, Thavathiru E, Ramalingam S, et al. Wnt inhibitory factor 1 induces apoptosis and inhibits cervical cancer growth, invasion and angiogenesis in vivo. Oncogene. 2012;31(22):2725-2737. doi:10.1038/onc.2011.455

25. Wang R, Geng N, Zhou Y, et al. Aberrant Wnt-1/beta-catenin signaling and WIF-1 deficiency are important events which promote tumor cell invasion and metastasis in salivary gland adenoid cystic carcinoma. Biomed Mater Eng. 2015;26(Suppl 1):S2145-S2153. doi:10.3233/BME-151520

26. Wu J, Fang J, Yang $Z$, et al. Wnt inhibitory factor-1 regulates glioblastoma cell cycle and proliferation. J Clin Neurosci. 2012;19 (10):1428-1432. doi:10.1016/j.jocn.2011.12.023

27. Huang Y, Du Q, Wu W, et al. Rescued expression of WIF-1 in gallbladder cancer inhibits tumor growth and induces tumor cell apoptosis with altered expression of proteins. Mol Med Rep. 2016;14(3):2573-2581. doi:10.3892/mmr.2016.5532

28. Ramachandran I, Ganapathy V, Gillies E, et al. Wnt inhibitory factor 1 suppresses cancer stemness and induces cellular senescence. Cell Death Dis. 2014;5:e1246. doi:10.1038/cddis.2014.219

29. Zhou Y, Li Z, Ding Y, et al. Promoter methylation of WNT inhibitory factor-1 may be associated with the pathogenesis of multiple human tumors. J Cancer Res Ther. 2018;14:S381-S387. doi:10.4103/09731482.235357

30. Zhao Z, Liu W, Liu J, et al. The effect of EBV on WIF1, NLK, and APC gene methylation and expression in gastric carcinoma and nasopharyngeal cancer. $J$ Med Virol. 2017;89(10):1844-1851. doi:10.1002/jmv.24863

31. Lin B, Hong H, Jiang X, et al. WNT inhibitory factor 1 promoter hypermethylation is an early event during gallbladder cancer tumorigenesis that predicts poor survival. Gene. 2017;622:42-49. doi:10.1016/j.gene.2017.04.034

32. Roperch JP, Incitti R, Forbin S, et al. Aberrant methylation of NPY, PENK, and WIF1 as a promising marker for blood-based diagnosis of colorectal cancer. BMC Cancer. 2013;13:566. doi:10.1186/14712407-13-566

33. Lee SM, Park JY, Kim DS. Wif1 hypermethylation as unfavorable prognosis of non-small cell lung cancers with EGFR mutation. Mol Cells. 2013;36(1):69-73. doi:10.1007/s10059-013-0060-7

34. Yan TF, Wu MJ, Xiao B, et al. Knockdown of HOXC6 inhibits glioma cell proliferation and induces cell cycle arrest by targeting WIF-1 in vitro and vivo. Pathol Res Pract. 2018;214(11):1818-1824. doi:10.1016/j.prp.2018.09.001
35. Jiang $\mathrm{Y}$, Li $\mathrm{Z}$, Zheng $\mathrm{S}$, et al. The long non-coding RNA HOTAIR affects the radiosensitivity of pancreatic ductal adenocarcinoma by regulating the expression of Wnt inhibitory factor 1. Tumour Biol. 2016;37(3):3957-3967. doi:10.1007/s13277-0154234-0

36. Ji D, Chen Z, Li M, et al. MicroRNA-181a promotes tumor growth and liver metastasis in colorectal cancer by targeting the tumor suppressor WIF-1. Mol Cancer. 2014;13:86. doi:10.1186/14764598-13-86

37. Li C, Wang Z, Chen S, et al. MicroRNA-552 promotes hepatocellular carcinoma progression by downregulating WIF1. Int J Mol Med. 2018;42(6):3309-3317. doi:10.3892/ijmm.2018.3882

38. Feng ZY, Xu XH, Cen DZ, et al. miR-590-3p promotes colon cancer cell proliferation via Wnt/ $\beta$-catenin signaling pathway by inhibiting WIF1 and DKK1. Eur Rev Med Pharmacol Sci. 2017;21 (21):4844-4852.

39. Guo M, Zhang X, Wang G, et al. miR-603 promotes glioma cell growth via Wnt/ $\beta$-catenin pathway by inhibiting WIF1 and CTNNBIP1. Cancer Lett. 2015;360(1):76-86. doi:10.1016/j. canlet.2015.02.003

40. Sundov D, Petric Mise B, Mrklic I, et al. Prognostic significance of MAPK, Topo II $\alpha$ and E-cadherin immunoexpression in ovarian serous carcinomas. Neoplasma. 2017;64(2):289-298. doi:10.4149/ neo 2017217

41. Chen D, Maruschke M, Hakenberg O, et al. TOP2A, HELLS, ATAD2, and TET3 are novel prognostic markers in renal cell carcinoma. Urology. 2017;102:265. doi:10.1016/j. urology.2016.12.050

42. An X, Xu F, Luo R, et al. The prognostic significance of topoisomerase II alpha protein in early stage luminal breast cancer. $B M C$ Cancer. 2018;18(1):331. doi:10.1186/s12885-018-4170-7

43. Zhou Z, Liu S, Zhang M, et al. Overexpression of topoisomerase 2-alpha confers a poor prognosis in pancreatic adenocarcinoma identified by co-expression analysis. Dig Dis Sci. 2017;62 (10):2790-2800. doi:10.1007/s10620-017-4718-4

44. Liu LP, Yang M, Peng QZ, et al. UBE2T promotes hepatocellular carcinoma cell growth via ubiquitination of p53. Biochem Biophys Res Commun. 2017;493(1):20-27. doi:10.1016/j. bbrc.2017.09.091

45. Luo C, Yao Y, Yu Z, et al. UBE2T knockdown inhibits gastric cancer progression. Oncotarget. 2017;8(20):32639-32654. doi:10.18632/ oncotarget. 15947

46. Wang Y, Leng $H$, Chen $H$, et al. Knockdown of UBE2T inhibits osteosarcoma cell proliferation, migration, and invasion by suppressing the PI3K/Akt signaling pathway. Oncol Res. 2016;24 (5):361-369. doi:10.3727/096504016X14685034103310

47. $\mathrm{Hu} \mathrm{W}$, Xiao L, Cao C, et al. UBE2T promotes nasopharyngeal carcinoma cell proliferation, invasion, and metastasis by activating the AKT/GSK3 $\beta / \beta$-catenin pathway. Oncotarget. 2016;7 (12):15161-15172. doi:10.18632/oncotarget.7805

48. Wen M, Kwon Y, Wang Y, et al. Elevated expression of UBE2T exhibits oncogenic properties in human prostate cancer. Oncotarget. 2015;6(28):25226-25239. doi:10.18632/oncotarget.4712

49. Guo W, Dong Z, Guo Y, et al. Decreased expression and frequent promoter hypermethylation of RASSF2 and RASSF6 correlate with malignant progression and poor prognosis of gastric cardia adenocarcinoma. Mol Carcinog. 2016;55(11):1655-1666. doi:10.1002/mc.22416

50. Gharanei S, Brini AT, Vaiyapuri S, et al. RASSF2 methylation is a strong prognostic marker in younger age patients with Ewing sarcoma. Epigenetics. 2013;8(9):893-898. doi:10.4161/epi.25617

51. Endoh M, Tamura G, Honda T, et al. RASSF2, a potential tumour suppressor, is silenced by $\mathrm{CpG}$ island hypermethylation in gastric cancer. $\mathrm{Br} J$ Cancer. 2005;93(12):1395-1399. doi:10.1038/sj. bjc. 6602854 
52. Li H, Zhang W, Yan M, et al. Nucleolar and spindle associated protein 1 promotes metastasis of cervical carcinoma cells by activating Wnt/ $\beta$-catenin signaling. J Exp Clin Cancer Res. 2019;38(1):33. doi:10.1186/s13046-019-1037-y

53. Han G, Wei Z, Cui H, et al. NUSAP1 gene silencing inhibits cell proliferation, migration and invasion through inhibiting DNMT1 gene expression in human colorectal cancer. Exp Cell Res. 2018;367(2):216-221. doi:10.1016/j.yexcr.2018.03.039
54. Gordon CA, Gong X, Ganesh D, et al. NUSAP1 promotes invasion and metastasis of prostate cancer. Oncotarget. 2017;8 (18):29935-29950. doi:10.18632/oncotarget.15604

\section{Publish your work in this journal}

OncoTargets and Therapy is an international, peer-reviewed, open access journal focusing on the pathological basis of all cancers, potential targets for therapy and treatment protocols employed to improve the management of cancer patients. The journal also focuses on the impact of management programs and new therapeutic

Submit your manuscript here: https://www.dovepress.com/oncotargets-and-therapy-journal agents and protocols on patient perspectives such as quality of life, adherence and satisfaction. The manuscript management system is completely online and includes a very quick and fair peer-review system, which is all easy to use. Visit http://www.dovepress.com/ testimonials.php to read real quotes from published authors. 